\title{
Effect of Temperature on the Thermal Conductivity of Rocks and Its Implication for In Situ Correction
}

\author{
Chi Chen, ${ }^{1,2}$ Chuanqing Zhu $\mathbb{D}^{1,2}$ Baoshou Zhang, ${ }^{3}$ Boning Tang $\mathbb{D}^{1,2}$ Kunyu Li, ${ }^{4}$ \\ Wenzheng $\mathrm{Li}^{5}{ }^{5}$ and Xiaodong $\mathrm{Fu}^{5}$ \\ ${ }^{1}$ College of Geosciences, China University of Petroleum, Beijing, Beijing 102249, China \\ ${ }^{2}$ State Key Laboratory of Petroleum Resources and Prospecting, China University of Petroleum, Beijing, Beijing 102249, China \\ ${ }^{3}$ Tarim Oilfield Company, PetroChina, Korla, Xinjiang 841000, China \\ ${ }^{4}$ Exploration and Development Research Institute, PetroChina Southwest Oil \& Gasfield Company, Chengdu, Sichuan 610041, China \\ ${ }^{5}$ PetroChina Hangzhou Institute of Geology, Hangzhou 310023, China
}

Correspondence should be addressed to Chuanqing Zhu; zhucq@cup.edu.cn

Received 30 December 2020; Revised 17 April 2021; Accepted 20 April 2021; Published 4 May 2021

Academic Editor: Xiaorong Luo

Copyright $(2021$ Chi Chen et al. This is an open access article distributed under the Creative Commons Attribution License, which permits unrestricted use, distribution, and reproduction in any medium, provided the original work is properly cited.

\begin{abstract}
Detailed knowledge of the effects of temperature on the thermal conductivity $(\lambda)$ of rocks is essential for investigating the geothermal regime of basins and their thermal evolution. In this study, the $\lambda$ of four rock types (carbonate, clastic, intrusive, and volcanic rocks) were measured at temperatures of $25^{\circ} \mathrm{C}, 50^{\circ} \mathrm{C}, 100^{\circ} \mathrm{C}, 150^{\circ} \mathrm{C}, 200^{\circ} \mathrm{C}, 250^{\circ} \mathrm{C}$, and $300^{\circ} \mathrm{C}$ using the Transient Plane Source (TPS) approach, which is accurate to $\pm 3 \%$. Experimental results demonstrate that the $\lambda$ of carbonate and clastic specimens decrease strongly with increasing temperature. In contrast, the $\lambda$ of intrusive and volcanic rocks are relatively insensitive to temperature. The temperature (T) dependence of $\lambda$ can be classified into three groups in terms of the value of $\lambda$ at $25^{\circ} \mathrm{C}$. The first group is composed of rocks characterized by high $\lambda(>4.5 \mathrm{~W} / \mathrm{m} \cdot \mathrm{K})$ at room temperature, for which the curves of $\lambda-T$ exhibit a concave pattern. The second group consists of rocks with a moderate $\lambda(2.5 \sim 3.5 \mathrm{~W} / \mathrm{m} \cdot \mathrm{K})$, in which the curves tend to be a straight line. The last group comprises rocks with a low $\lambda(<2.5 \mathrm{~W} / \mathrm{m} \cdot \mathrm{K})$, exhibiting convex curves. There exists a close relationship between the $\lambda$ at $25^{\circ} \mathrm{C}$ and its rate of decrease $(\alpha)$. The absolute value of $\alpha$ increases with the $\lambda$ at $25^{\circ} \mathrm{C}$ rising. The relationship between the two values can be fitted by the equation $y=a x+b(1 / x)+c$ to derive the fitting parameters $a$, $b$, and $c$; by this equation with known fitting parameters, the $\lambda$ of the deep carbonate rocks of the Tarim Basin have been estimated.
\end{abstract}

\section{Introduction}

Thermal conductivity of rocks is an essential parameter in many fields such as constraining the dynamic evolution of planets, exploring the thermal state of basins, and utilizing geothermal resource. A large number of studies have been conducted on the calculation of heat flow and temperature in deep strata with demand for the exact data of thermal conductivity in situ, which cannot, however, be directly measured because of the limitation of current technology. Moreover, theoretic calculation is also impossible on account of extreme complicated structure of rocks. To date, experimental measurements in high temperature or pressure are the sole approach to attain situ thermal conductivity of rocks. There exist only a few studies focusing on the factors influencing thermal conductivity for rocks in recent years. [1-5]. Initially, Birch and Clark [6] measured the $\lambda$ of several rocks by adopting the steady method with rising temperature. The experimental results showed that the $\lambda$ of all samples were between 1.67 and $5.86 \mathrm{~W} / \mathrm{m} \cdot \mathrm{K}$, and the $\lambda$ of feldspar aggregates and glasses with low-conductivity increased as temperature rise, whereas those samples having a high conductivity showed a negative temperature dependence. A simple equation, $\lambda=1 /(A+B \times T)$, to describe the relationship between the $\lambda$ and $T$ was proposed by Seipold (1998), in which $A$ and $B$, controlled by the lithology, are the fitting coefficients. This study seemed to reveal a generalized conclusion that rocks with a relatively high thermal conductivity exhibit a stronger decrease in thermal conductivity with increasing temperature than those with lower $\lambda$. 


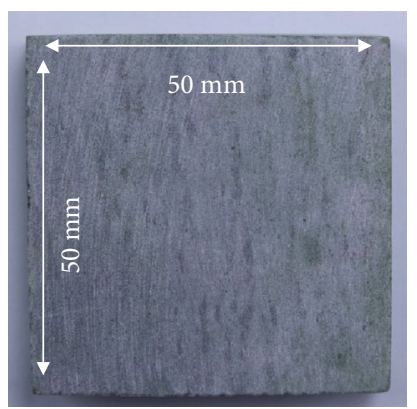

(a)

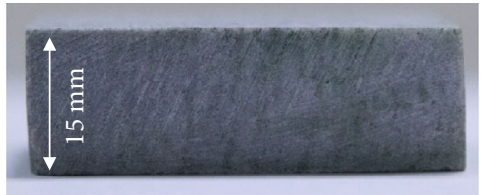

(b)

FIGURE 1: Representative specimen prepared for thermal conductivity measurements. (a) Top view. (b) Side view.

Vosteen and Schellschmidt [7] obtained the $\lambda$ of magmatic, metamorphic, and sedimentary rocks using transient methods. Their results indicated that the value of $\lambda$ at $0^{\circ} \mathrm{C}$ governs the temperature dependence of $\lambda$ in rocks, consistent with Seipold (1998). Abdulagatov et al. [8] employed a steady method to determinate $\lambda$ of five rocks (sandstone, limestone, amphibolite, granulite, and pyroxene-granulite) at temperature between $0^{\circ} \mathrm{C}$ and $150^{\circ} \mathrm{C}$ and high pressure simultaneously. Their results demonstrated a nearly linear temperature dependence of the $\lambda$. Although the above-mentioned studies provide useful insights into the temperature dependence of $\lambda$ for rocks, the knowledge of temperature effect on $\lambda$ need to be improved.

The aims of the present study are (1) to develop a novel model to predict $\lambda$ as a function of temperature and (2) to provide a basis for the correction of $\lambda$ at high temperature.

\section{Samples and Methods}

2.1. Sample Information. Twenty-eight rock specimens of outcrops are collected, including twelve carbonates, five clastic rocks, six intrusive rocks, and five volcanic rocks. To ensure the universality and impersonality of experimental results, these opted samples are not restricted in one local region, but locates in a wide range of sedimentary basins or structural belts, involving North China Plain, Sichuan Basin, Tarim Basin, Songliao Basin, etc. To rule out rock structure effect on thermal conductivity, all samples chosen for the study were homogeneous and isotropic at hand scale, with no visible bedding or cracks. All specimens were deposited in a dry environment at room temperature and atmospheric pressure. Each sample was prepared as two cuboids of $50 \mathrm{~mm}$ length, $50 \mathrm{~mm}$ width, and $15 \mathrm{~mm}$ thickness for thermal conductivity measurements (Figure 1). The surfaces of the processed cuboids must be as flat as possible. Even though there is a little microirregularity on the sample's surface, a strong contact thermal resistance can be produced leading to fluctuating results. To ensure this, each sample surface in contact with the probe (introduced in the following text) must be polished. Detailed descriptions and physical parameters of the analyzed specimens are listed in Table 1.

2.2. Methods. Over the past decades, methods in thermal analyses have been substantially improved in accuracy and expanded to dozens of secondary approaches. According to the status of temperature field inside the measured samples, these experimental techniques can be classified into two groups. (1) Steady methods: these ones feature a steady temperature field across the sample throughout the measurement process and were extensively employed in the past. High accuracy is their most prominent strength. However, its price is rather time-consuming and expensive. It will take five to seven hours to wait for the establishment of steady temperature field. For these disadvantages, steady methods have been hardly employed in the studies of rocks or minerals in recent years. (2) Transient methods: contrary to steady methods, transient methods have a variable temperature field in the interior of samples throughout transient measurements. By contrast, an outstanding upside of transient methods is time-saving and cheaper. The measurement process duration typically ranges from a couple of seconds to a few minutes. In the past, they are less accurate than steady methods. By decades of improvement and development, transient methods have been accurate enough for the determination of rocks now. Most researchers preferred to them, so the reliability of these approaches have been thus validated. The major transient methods are as follows: (1) optical scanning (uncertainty 2\%) [9], (2) need-probe (uncertainty $5 \%$ ) [10], (3) hot wire (uncertainty 4\%) [11, 12], and (4) transient plane source (TPS) (uncertainty $3 \%$ ) [13]. In this study, TPS method was employed.

The TPS method is based on the principle of plane transient heat conduction in an infinite medium, which ensures that heat flow transporting through the specimen cannot reach its boundaries. After the measured sample is fixed in the sample-holder, waiting time of three minutes at least was required to achieve the thermal equilibrium between the measured specimen and the probe, before each starting of measurement. Upon reaching this state, the specimen was heated by the probe, producing a thermal disturbance in the temperature field within the specimen. Since the thermal conductivities of materials are diverse, the corresponding temperature rise varies. Specimens with good thermal conducting properties are characterized by rapid heat transport inside the specimens, and the probe temperature rise is relatively slow and low. In contrast, for specimens with good thermal insulation properties, the probe temperature rises rapidly, and heat is transported slowly. 
TABLE 1: Description and physical parameters of the analyzed specimens.

\begin{tabular}{|c|c|c|c|c|}
\hline No. & Petrology & Description & Density $\left(\mathrm{g} / \mathrm{cm}^{3}\right)$ & Effective porosity (\%) \\
\hline $\mathrm{Ca}-01$ & Dolomite & Gray, micrite & 2.840 & 0.6 \\
\hline $\mathrm{Ca}-02$ & Dolomite & Gray, micrite & 2.785 & 0.4 \\
\hline $\mathrm{Ca}-03$ & Dolomite & Black gray, micrite & 2.841 & 0.4 \\
\hline $\mathrm{Ca}-04$ & Dolomite & Gray, micrite & 2.847 & 0.6 \\
\hline $\mathrm{Ca}-05$ & Dolomite & Gray, micrite & 2.850 & 0.5 \\
\hline $\mathrm{Ca}-06$ & Dolomite & Gray, micrite & 2.834 & 0.3 \\
\hline $\mathrm{Ca}-07$ & Limestone & Black gray, micrite & 2.706 & 0.2 \\
\hline $\mathrm{Ca}-08$ & Limestone & Gray, micrite & 2.795 & 0.7 \\
\hline $\mathrm{Ca}-09$ & Lime-dolomite & Gray, micrite & 2.858 & 0.1 \\
\hline $\mathrm{Ca}-10$ & Lime-dolomite & Gray, micrite & 2.836 & 0.2 \\
\hline $\mathrm{Ca}-11$ & Lime-dolomite & Gray, micrite & 2.820 & 0.3 \\
\hline $\mathrm{Ca}-12$ & Marble & White, coarse grain & 2.834 & 0.1 \\
\hline $\mathrm{Cl}-01$ & Sandstone & Gray, middle grain & 2.562 & 3.4 \\
\hline $\mathrm{Cl}-02$ & Sandstone & Gray, middle grain & 2.623 & 4.2 \\
\hline $\mathrm{Cl}-03$ & Mudstone & Red, fine grain & 2.838 & 1.7 \\
\hline $\mathrm{Cl}-04$ & Mudstone & Light red, fine grain & 2.610 & 2.3 \\
\hline $\mathrm{Cl}-05$ & Conglomerate & Dark yellow, coarse grain & 2.616 & 3.5 \\
\hline In-01 & Fraidornite & Dark gray, fine grain & 2.803 & 0.2 \\
\hline In-02 & Lamprophyre & Dark gray, fine grain & 2.677 & 0.1 \\
\hline In-03 & Diabase & Dark gray, fine grain & 3.051 & 0.6 \\
\hline In-04 & Granite & Light yellow, coarse grain & 2.653 & 0.4 \\
\hline In-05 & Diorite & Gray, fine grain & 3.077 & 0.3 \\
\hline In-06 & Gabbro & Gray, fine grain & 2.829 & 0.2 \\
\hline Vo-01 & Perlite & Black, aphanitic & 2.319 & 4.7 \\
\hline Vo-02 & Andesite-basalt & Dark gray, fine grain & 2.808 & 0.3 \\
\hline Vo-03 & Pitch stone & Magenta, fine grain & 2.277 & 6.1 \\
\hline Vo-04 & Felsite & Light yellow, fine grain & 2.558 & 3.9 \\
\hline Vo-05 & Spilite & Light gray, fine grain & 2.869 & 5.2 \\
\hline
\end{tabular}

The temperature rise $(\Delta \bar{T})$ and the dimensionless time function $\left(D_{s}(\tau)\right)$ can be fitted as a linear function (Equation (1)). The slope of the straight line obtained is a function of the value of $\lambda$ in the measured specimen. The corresponding temperature rise can be expressed as:

$$
\begin{aligned}
\Delta \bar{T}(\tau) & =\frac{P_{o}}{\pi^{3 / 2} r \lambda} D_{s}(\tau), \\
\tau & =\frac{\sqrt{\alpha t}}{r}=\sqrt{\frac{t}{\theta}} \\
\theta & =\frac{r^{2}}{\alpha}
\end{aligned}
$$

where $\Delta \bar{T}(\tau)$ is the mean temperature rise in the probe, $P_{0}$ is the total output power of the probe, $r$ is the radius of the probe, $\lambda$ is the thermal conductivity of the specimen, $\tau$ is a dimensionless function, depending on time, $\alpha$ is the thermal diffusivity of the specimen, $t$ is the measurement time from the start of the transient recording, and $\theta$ is the characteristic time. According to Equation (1), $\lambda$ can be calculated as the following:

$$
\lambda=\frac{P_{o}}{\pi^{3 / 2} r k}
$$

where $k$, which is known, represents the slope of the line.

2.3. Equipment and Measurements. In this work, a Hot Disk TPS2500S (Figure 2(a)) was adopted to measure the $\lambda$ value of the analyzed specimens. The apparatus measures thermal conductivity of materials ranging from 0.005 to $500 \mathrm{~W} / \mathrm{m} \cdot \mathrm{K}$ in accuracy and reproducibility better than $3 \%$ and $1 \%$, respectively. The core component of the apparatus is a thin double spiral probe, etched out of a thin nickel foil (Figure 2(b)), which is sandwiched between two sheets of polyimide electrical insulator. A constant direct current is applied to the probe, causing its surface temperature to rise and the electric resistance of the nickel wire inside the probe increases simultaneously. The temperature of the surface of the specimen is associated with the resistance of nickel wire based on the known equation constraining temperature and 


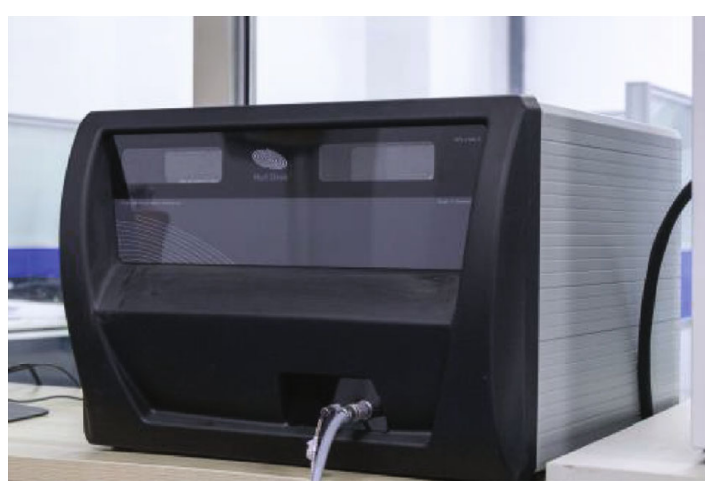

(a)

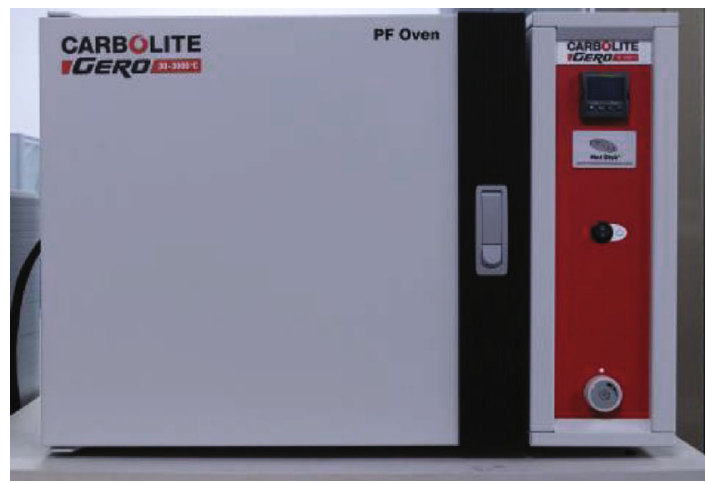

(c)

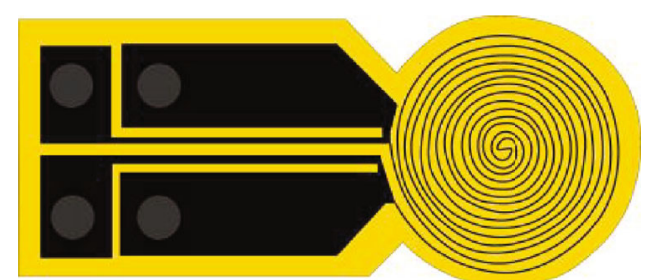

(b)

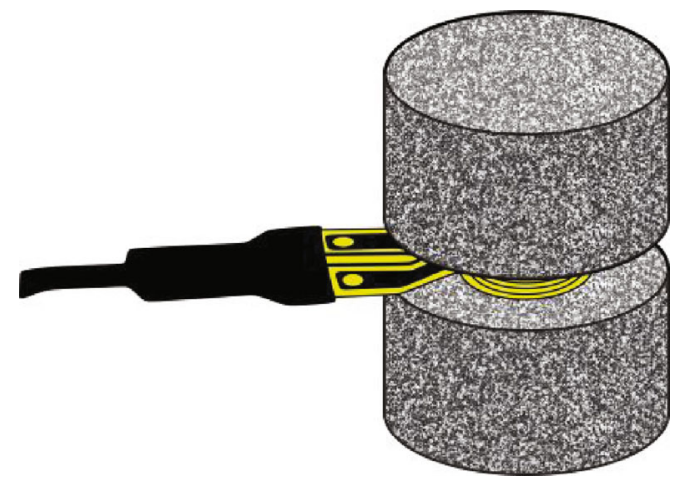

(d)

Figure 2: The Hot Disk TPS2500S system used for analysis. (a) TPS 2500 s; (b) Hot Disk probe 5501; (c) temperature controller; (d) schematic diagram of the transient plane source method.

resistance. The probe acts as both the heat source and a temperature recorder.

Prior to thermal conductivity measurements, the specimens were soaked in an acetone solution for $3 \mathrm{~h}$ in order to remove oil at the surface, cleaned using an ultrasonic cleaner, and placed in an oven at $50^{\circ} \mathrm{C}$ for $48 \mathrm{~h}$ to dry. Subsequently, the specimens were baked at $100^{\circ} \mathrm{C}$ for $5 \mathrm{~h}$ to remove adsorbed water. Thermal conductivity measurements were conducted at $25^{\circ} \mathrm{C}, 50^{\circ} \mathrm{C}, 100^{\circ} \mathrm{C}, 150^{\circ} \mathrm{C}, 200^{\circ} \mathrm{C}, 250^{\circ} \mathrm{C}$, and $300^{\circ} \mathrm{C}$. The temperature was controlled by the PF Oven (Figure 2(c)), which is capable of controlling temperature within a range of just $\pm 0.5^{\circ} \mathrm{C}$ for $30 \mathrm{~min}$. Herein, we set the interval time between two adjacent measurements as ten minutes, which is more than three minutes of official recommendations. Two specimens were tightly clamped together to ensure the inexistence of an air gap between the specimens and the probe (Figure 2(d)). Three repeated measurements are conducted at each temperature to check the reproducibility, and their averages are regarded as the final result. Generally, one temperature sequence measurement required at least twelve hours.

\section{Results}

Experimental results are listed in Table 2 and shown in Figure 3. At room temperature $\left(25^{\circ} \mathrm{C}\right)$, the average thermal conductivity is $5.03 \pm 1.20 \mathrm{~W} / \mathrm{m} \cdot \mathrm{K}$ and $3.43 \pm 1.48 \mathrm{~W} / \mathrm{m} \cdot \mathrm{K}$ for carbonate and clastic samples, which is obviously greater than that of the intrusive and volcanic rocks, $2.09 \pm 0.29 \mathrm{~W} /$ $\mathrm{m} \cdot \mathrm{K}$ and $1.57 \pm 0.41 \mathrm{~W} / \mathrm{m} \cdot \mathrm{K}$, respectively. Standard deviation shows a more concentrated distribution of thermal conductivity for intrusive and volcanic rocks at room temperature, as confirmed by Figure 3 . Thermal conductivity of most samples decreases as temperature rises except for a few intrusive and volcanic samples. Although majority of samples exhibit a decrease in thermal conductivity with temperature increase, there are considerable discrepancy in the slope $d \lambda / d T$ and the extent of decrease from $25^{\circ} \mathrm{C}$ to $300^{\circ} \mathrm{C}$ among these samples. As shown in Figure 3, the intrusive and volcanic samples exhibit a gentler decrease compared with the others.

\section{Discussion}

4.1. Major Influencing Factors of Rock Thermal Conductivity. Thermal conductivity of rocks at a fixed temperature is dominated by internal factors, including composition, porosity, and structure. From Figure 3, the dolomite rocks have approximately twice the thermal conductivity of the marble and limestone. Such a difference can be explained by their composition. Dolomite, a major mineral in dolomite rocks, has a lager thermal conductivity of $13.16 \mathrm{~W} / \mathrm{m} \cdot \mathrm{K}$ as compared to $8.58 \mathrm{~W} / \mathrm{m} \cdot \mathrm{K}$ of the calcite, a main mineral in limestones[14]. However, thermal conductivity of dolomite and 
TABLE 2: Measured values of thermal conductivity at various temperatures.

\begin{tabular}{|c|c|c|c|c|c|c|c|}
\hline \multirow{2}{*}{ No. } & \multicolumn{7}{|c|}{ Thermal conductivity at different temperature $(\mathrm{W} / \mathrm{m} \cdot \mathrm{K})$} \\
\hline & $25^{\circ} \mathrm{C}$ & $50^{\circ} \mathrm{C}$ & $100^{\circ} \mathrm{C}$ & $150^{\circ} \mathrm{C}$ & $200^{\circ} \mathrm{C}$ & $250^{\circ} \mathrm{C}$ & $300^{\circ} \mathrm{C}$ \\
\hline $\mathrm{Ca}-01$ & 6.15 & 5.69 & 4.87 & 4.17 & 3.63 & 3.14 & 2.69 \\
\hline $\mathrm{Ca}-02$ & 5.64 & 5.25 & 4.61 & 4.03 & 3.57 & 3.15 & 2.74 \\
\hline $\mathrm{Ca}-03$ & 6.10 & 5.63 & 4.99 & 4.34 & 3.90 & 3.47 & 2.99 \\
\hline $\mathrm{Ca}-04$ & 5.77 & 5.33 & 4.85 & 4.36 & 3.94 & 3.65 & 3.33 \\
\hline $\mathrm{Ca}-05$ & 6.53 & 6.00 & 5.23 & 4.45 & 3.93 & 3.44 & 2.89 \\
\hline $\mathrm{Ca}-06$ & 5.79 & 5.36 & 4.87 & 4.35 & 3.96 & 3.62 & 3.23 \\
\hline $\mathrm{Ca}-07$ & 2.89 & 2.75 & 2.56 & 2.35 & 2.13 & 1.95 & 1.78 \\
\hline $\mathrm{Ca}-08$ & 3.19 & 3.11 & 3.02 & 2.89 & 2.76 & 2.67 & 2.48 \\
\hline $\mathrm{Ca}-09$ & 5.13 & 4.86 & 4.41 & 3.97 & 3.61 & 3.33 & 3.01 \\
\hline Ca-10 & 5.06 & 4.73 & 4.14 & 3.64 & 3.20 & 2.83 & 2.47 \\
\hline Ca-11 & 4.82 & 4.37 & 3.82 & 3.43 & 3.10 & 2.78 & 2.45 \\
\hline $\mathrm{Ca}-12$ & 3.26 & 3.22 & 3.08 & 2.88 & 2.65 & 2.48 & 2.28 \\
\hline Cl-01 & 3.16 & 3.10 & 2.95 & 2.73 & 2.60 & 2.43 & 2.23 \\
\hline Cl-02 & 6.25 & 5.80 & 5.10 & 4.47 & 3.95 & 3.60 & 3.21 \\
\hline $\mathrm{Cl}-03$ & 2.54 & 2.48 & 2.41 & 2.30 & 2.21 & 2.12 & 1.99 \\
\hline Cl-04 & 2.01 & 2.06 & 2.08 & 2.03 & 1.96 & 1.93 & 1.83 \\
\hline Cl-05 & 3.20 & 3.06 & 2.84 & 2.60 & 2.42 & 2.27 & 2.11 \\
\hline In-01 & 1.84 & 1.93 & 1.96 & 1.97 & 1.88 & 1.86 & 1.80 \\
\hline In-02 & 2.01 & 2.08 & 2.11 & 2.06 & 1.98 & 1.89 & 1.81 \\
\hline In-03 & 1.68 & 1.75 & 1.81 & 1.82 & 1.81 & 1.80 & 1.74 \\
\hline In-04 & 2.18 & 2.11 & 2.11 & 2.05 & 1.97 & 1.89 & 1.77 \\
\hline In-05 & 2.56 & 2.46 & 2.46 & 2.41 & 2.35 & 2.29 & 2.17 \\
\hline In-06 & 2.24 & 2.21 & 2.22 & 2.17 & 2.10 & 2.02 & 1.89 \\
\hline Vo-01 & 1.10 & 1.11 & 1.29 & 1.32 & 1.32 & 1.19 & 1.12 \\
\hline Vo-02 & 1.60 & 1.66 & 1.73 & 1.74 & 1.72 & 1.71 & 1.66 \\
\hline Vo-03 & 1.14 & 1.22 & 1.31 & 1.35 & 1.34 & 1.26 & 1.17 \\
\hline Vo-04 & 1.88 & 1.89 & 1.82 & 1.70 & 1.59 & 1.51 & 1.43 \\
\hline Vo-05 & 2.14 & 2.20 & 2.15 & 2.08 & 2.02 & 1.95 & 1.86 \\
\hline
\end{tabular}

calcite is much more than their corresponding rocks. This is because there exists thermal resistance on the grain boundary as well as imperfection and defect inside the crystal within a rock. For clastic rocks, the large value of $6.25 \mathrm{~W} / \mathrm{m} \cdot \mathrm{K}$ may be attributed to the incorporation of quartz. Quartz is a common mineral in clastic rocks and has a considerable thermal conductivity of up to $18.37 \mathrm{~W} / \mathrm{m} \cdot \mathrm{K}[15]$. Compared with the carbonate and clastic rocks, intrusive and volcanic rocks alike exhibit a lower thermal conductivity ranging from $1.10 \mathrm{~W} / \mathrm{m} \cdot \mathrm{K}$ to $2.56 \mathrm{~W} / \mathrm{m} \cdot \mathrm{K}$ and more concentrated distribution. The low thermal conductivity may be due to the low thermal conductivity of the minerals composed of igneous rocks. For example, feldspar, the most common and abundant mineral in Earth's crust, has a thermal conductivity just from 1.50 to $2.50 \mathrm{~W} / \mathrm{m} \cdot \mathrm{K}[15]$. The concentration of thermal conductivity can be because different types of igneous rocks have same types of forming-rock minerals. For instance, many igneous rocks have the same minerals of feldspar, biotite, and quartz. Though the range of thermal conductivity is different for the four types of rocks, their range largely over- lap each other. Therefore, lithology cannot be exactly distinguished only by relying on thermal conductivity.

4.2. Effect of Temperature on Thermal Conductivity. The $\lambda$ of almost all rocks, as presented in Figure 3, decreases with increasing temperature, consistent with expectations. Different from the previous studies $[5,16-18]$, a unique phenomenon, that the $\lambda$ of some intrusive and volcanic rocks firstly increases and then decreases with rising temperature, can be observed from Figures 3(c) and 3(d). This will be discussed in detail below. The $\lambda$ of carbonate and clastic rocks have a more evident decrease than intrusive and volcanic rocks. For carbonate and clastic rocks, the mean values of the temperature derivative of $\lambda$ are from -1.32 to $0.26 \mathrm{~W} / \mathrm{m} \cdot \mathrm{K} / 100^{\circ} \mathrm{C}$ and from -1.11 to $-0.07 \mathrm{~W} / \mathrm{m} \cdot \mathrm{K} / 100^{\circ} \mathrm{C}$, respectively. In contrast, the $\lambda$ of intrusive and volcanic rocks is universally insensitive to temperature, frequently presenting a slight increase or an increase followed by decrease. The mean values of the temperature derivatives for intrusive and volcanic rocks are only -0.15 to $+0.02 \mathrm{~W} / \mathrm{m} \cdot \mathrm{K} / 100^{\circ} \mathrm{C}$ and -0.16 to $+0.02 \mathrm{~W} / \mathrm{m} \cdot \mathrm{K} / 100^{\circ} \mathrm{C}$, respectively. The positive mean value demonstrates that the $\lambda$ at $300^{\circ} \mathrm{C}$ is greater than the value at room temperature, meaning a slight increase of $\lambda$. The rise in $\lambda$ should stem from the incorporation of amorphous materials, due to rapid crystallization of magma. Amorphous materials, the opposite of crystals, are solids that lack the long-range order, which is a typical characteristic of a crystal. It has been considered that the thermal conductivity of amorphous materials increases as temperature rise [19, 20]. Consequently, we speculate that rocks for which thermal conductivity initially increases and then decreases with temperature may be the mixtures of crystalline and amorphous constituents. Generally, amorphous constituents are just incorporated into volcanic rocks [21] due to rapid crystallization process, which is caused by the huge difference in temperature between the magma and the context at ground level. But a similar tendency to the volcanic rocks has been observed in intrusive rocks, which is normally produced in subsurface having a greater temperature than the ground level. This may occur because the intrusive rocks studied crystallize at swallow depths and, thus, at lower temperature, as may lead to a little formation of amorphous constituents in despite of being in underground. Additionally, an asymptotical convergence of $\lambda$ can be observed for carbonate and clastic rocks with increasing temperature, in agreement with previous studies $[1,3,8]$. The standard deviation of $\lambda$ at room temperature in carbonate and clastic rocks was $1.25 \mathrm{~W} / \mathrm{m} \cdot \mathrm{K}$ and $1.65 \mathrm{~W} / \mathrm{m} \cdot \mathrm{K}$, respectively. At a temperature of $300^{\circ} \mathrm{C}$, the corresponding value decreased to $0.44 \mathrm{~W} / \mathrm{m} \cdot \mathrm{K}$ and $0.54 \mathrm{~W} / \mathrm{m} \cdot \mathrm{K}$, respectively.

Based on the shape of the curves of $\lambda-T$ in Figure 3 , we obtain an empirical rule showing that the curves of $\lambda-T$, regardless of lithology, are governed by the value of $\lambda$ at $25^{\circ} \mathrm{C}$. This rule has been plotted in Figure 4 . These curves shown in Figure 4 can be classified into three groups. (1) The $\lambda$ of the specimens with the $\lambda$ values higher $4.5 \mathrm{~W} / \mathrm{m} \cdot \mathrm{K}$ at room temperature strongly decrease, and the absolute value of the temperature derivative of thermal conductivity $(\mathbb{d} \lambda / d T)$ gradually decreases. The resulting curves have a 


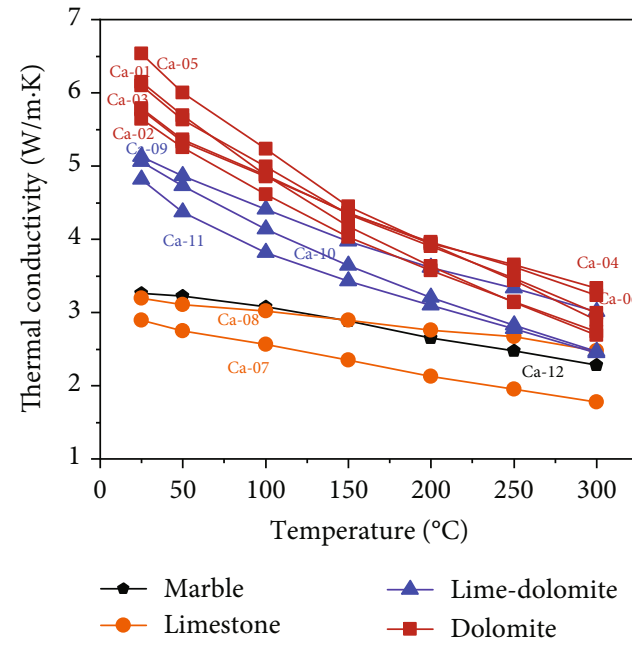

(a)

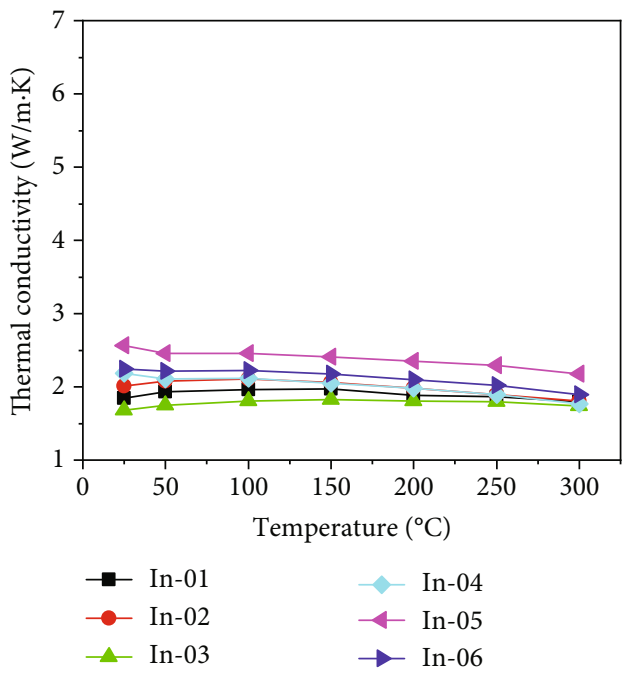

(c)

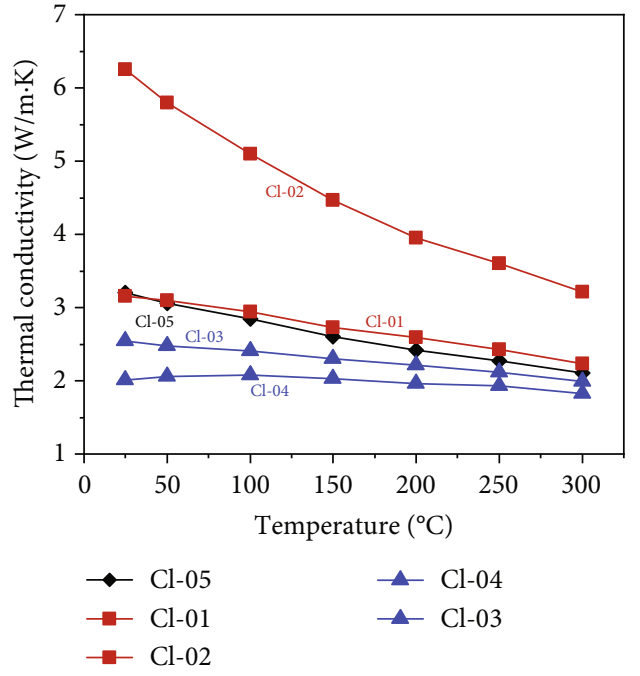

(b)

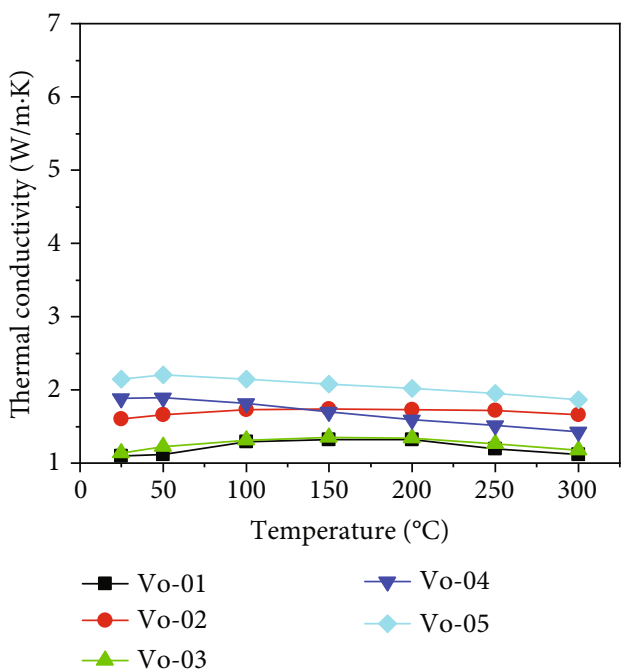

(d)

Figure 3: Temperature dependence of $\lambda$ in four rock types rocks. (a) Carbonates. (b) Clastic rocks. (c) Intrusive rocks. (d) Volcanic rocks.

concave pattern. (2) The $\lambda$ of the samples with $\lambda$ values of $2.5-3.5 \mathrm{~W} / \mathrm{m} \cdot \mathrm{K}$ at room temperature exhibit a near-linear decrease, and their temperature derivatives are approximately a constant. (3) The $\lambda$ of the samples having values below $2.5 \mathrm{~W} / \mathrm{m} \cdot \mathrm{K}$ either initially increase and then decrease or slightly increase. Irrespective of the trend observed in the last case, the influence of temperature is both minor. Experimental results analogous to the first group have been also observed in the studies headed by Seipold (1998) and Vosteen [7]. Therefore, the concave pattern shown in the first group may be a universal characteristic for those rocks with a high thermal conductivity $(>4.5 \mathrm{~W} / \mathrm{m} \cdot \mathrm{K})$. By contrast, the second and third cases have not been explicitly found in past publications yet. Unfortunately, the statistics have failed to be logically explained from a physical perspective at present. Despite all this, the rule can still provide a distinctive thinking that the $\lambda$ of rocks at high temperature can be statistically reflected though its $\lambda$ at room temperature.
According to the foregoing thought, the temperature effect can be quantified by defining a new term of $\alpha_{t}$, which means the decrease rate of $\lambda$ at temperature of $t$ :

$$
\alpha_{t}=\frac{\lambda_{t}-\lambda_{(25)}}{\lambda_{(25)}}
$$

in which $\alpha_{t}$ is the rate of decrease at temperature of $t, \lambda_{(25)}$ is the thermal conductivity at $25^{\circ} \mathrm{C}$, and $\lambda_{t}$ is the thermal conductivity at temperature of $t$. Based on the present data, we calculated the $\alpha_{t}$ at $50^{\circ} \mathrm{C}, 100^{\circ} \mathrm{C}, 150^{\circ} \mathrm{C}, 200^{\circ} \mathrm{C}, 250^{\circ} \mathrm{C}$, and $300^{\circ} \mathrm{C}$ for each sample. The obtained results are plotted in Figure 5. Equation $y=a x+b(1, /, x)+c$ was employed to fit the results, obtaining fitting parameters $a, b$, and $c$ (Table 3 ). The $R$-squared at different temperature are all nearly 0.90 except the temperature of $50^{\circ} \mathrm{C}$. 


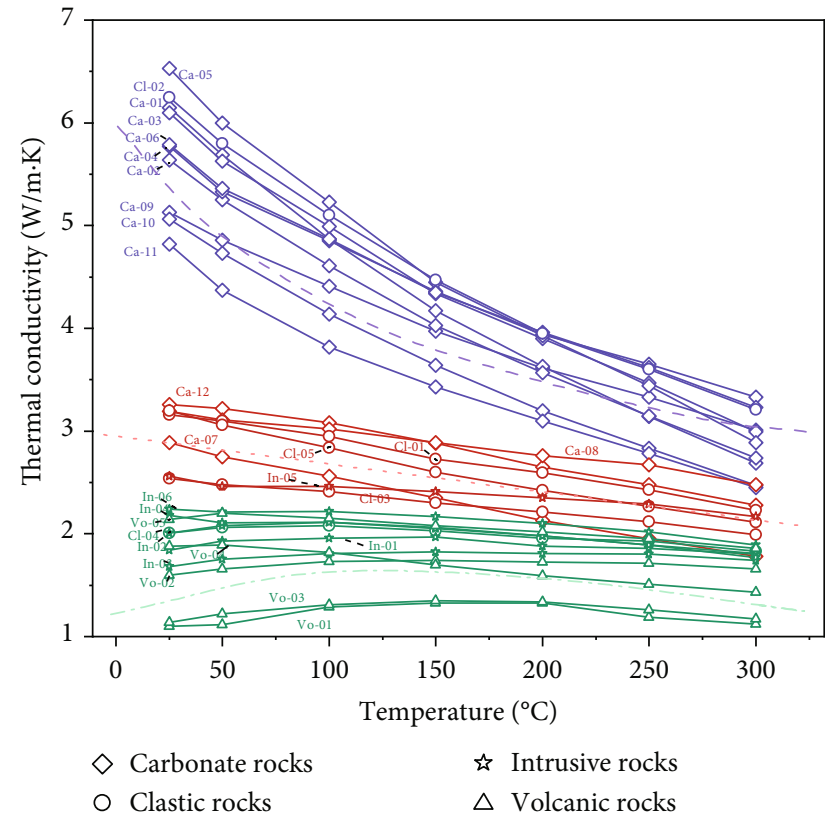

Figure 4: Schematic diagram of the three groups of thermal conductivity deduced as a function of temperature. Blue denotes samples with the $\lambda$ higher $4.5 \mathrm{~W} / \mathrm{m} \cdot \mathrm{K}$ at room temperature; red denotes samples with the $\lambda$ between 2.5 and $3.5 \mathrm{~W} / \mathrm{m} \cdot \mathrm{K}$ at room temperature; green denotes the samples with $\lambda$ below $2.5 \mathrm{~W} / \mathrm{m} \cdot \mathrm{K}$ at room temperature.

The generality of the method is validated by applying them to some independent data set from $([6,22]$. The Figure 6 presents the comparation of experimentally measured values with estimated values by current method. As a whole, the estimated values are consistent with measured values. Although some slight difference exists, this is possible due to the uncertainty of experiments. These discrepancies range from $-4.0 \%$ to $+3.5 \%$ with an average of $0.09 \%$, which is low enough for the estimation of thermal conductivity in the deep of a basin.

4.3. Implication for In Situ Thermal Conductivity. In the studies on temperature and heat flow of a basin, the situ thermal conductivity has long been roughly evaluated. Obviously, it is unclear. Studying thermal property of rocks under high temperature or pressure can provide better advices for these researches demanding precise thermal conductivity in situ. By rating the present findings to the previous temperature data published by others, the temperature effect of thermal conductivity of the deep carbonates in Tarim Basin has been estimated. From the paper [2], we collected the raw data of thermal conductivity for carbonate rocks in Tarim Basin from $4000 \mathrm{~m}$ to $7000 \mathrm{~m}$ depth, involving ten limestones and four dolomites (Table 4). In real strata condition, temperature, pressure, and fluid exert an impact on thermal conductivity. Temperature is negative, and pressure and fluid are positive $[19,21,23,24]$. Their combination makes the determination of in situ thermal conductivity more complicated and problematic. For a given rock, the characteristics of rocks such as porosity and mineral are closely linked with the influ- ence of external factors [25, 26]. According to the previous studies $[27,28]$, the effect of fluid on thermal conductivity depends chiefly on the porosity of rocks. The rocks with larger porosity will have a more remarkable increase in thermal conductivity. Further, the distribution and movement of fluid and thermal conductivity in dry conditions are also associated with the dependence of thermal conductivity. Especially for the rocks with low thermal conductivity in dry conditions, thermal conductivity can even be double at $100 \%$ water saturation [24]. Among the referred rocks, the five samples containing fluid have a small porosity ranging from $2.5 \%$ to $5.0 \%$. Hence, these samples are treated as dry ones. The effect of pressure depends on porosity and elastic modulus $[29,30]$. For the rocks having a large porosity, thermal conductivity will significantly increase. Generally, the pressure dependence of thermal conductivity can be divided two stages $[4,17,31]$. In the first, pressure can close the pores and cracks inside rocks, in which thermal conductivity will considerably expand. In the second, the pores and cracks are closed, and pressure increases thermal conductivity by enhancing the efficiency of heating transfer in crystal lattice [21], in which the increase of thermal conductivity is relatively small and slow. Because the porosity does not pronouncedly change from underground to ground, the pressure forced by the above strata is assumed just to act on the second stage. The pressure of rock matrix can be calculated by Equation (4).

$$
P=\left(\rho_{\text {rock }}-\rho_{\text {water }}\right) g H,
$$

in which $P$ is the pressure of rock matrix, $\rho_{\text {rock }}$ is the mean density of rocks of $2800 \mathrm{~kg} / \mathrm{m}^{3}, \rho_{\text {water }}$ is water density of $1000 \mathrm{~kg} / \mathrm{m}^{3}, g$ is net acceleration of $9.8 \mathrm{~N} / \mathrm{kg}$, and $H$ is the depth. By a simple calculation, $P$ is $141 \mathrm{MPa}$ at $8000 \mathrm{~m}$. According to the related studies $[4,8,21,32]$, pressure can increase thermal conductivity from $1 \%$ to $5 \%$ for the rocks with low porosity at the pressure of $150 \mathrm{MPa}$ in the second stage. If the depth of rocks is shallow, the effect will be more insignificant. The order of magnitude for increase in pressure is less than that of temperature. Therefore, the effect of pressure can be neglected in this correction.

Thermal conductivity of these samples is calculated at $50^{\circ} \mathrm{C}, 100^{\circ} \mathrm{C}, 150^{\circ} \mathrm{C}, 200^{\circ} \mathrm{C}, 250^{\circ} \mathrm{C}$, and $300^{\circ} \mathrm{C}$, using the parameters shown in Table 3. The results are illustrated in Figure 7. Since the in situ temperature of the samples is unknown, their temperature can only be obtained by calculation. Temperature at a certain depth can be formulated as:

$$
T=T_{0}+D \times \operatorname{grad} T,
$$

where $T$ is temperature at a certain depth, $T_{0}$ is land surface temperature, $D$ is depth, and $\operatorname{grad} T$ is geothermal gradient. In the light of the previous related studies, the gradT and $T_{0}$ in Tarim Basin is taken to $20.7^{\circ} \mathrm{C} / \mathrm{km}$ and $18^{\circ} \mathrm{C}[33]$, respectively. So, $T$ is calculated (as shown in Table 4). Each calculated temperature value is substituted to the corresponding curve to attain a point of intersection in Figure 8 . Its vertical coordinate is the corrected value of thermal conductivity (as exhibited in Table 4). The comparison between 


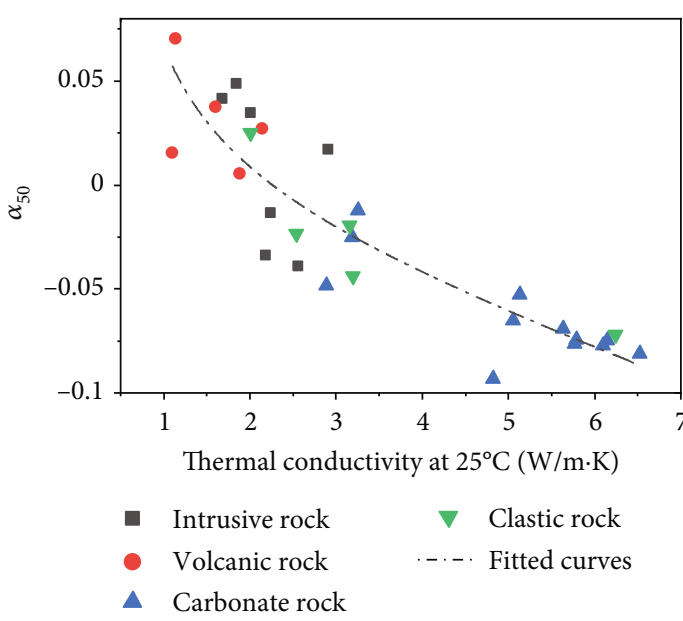

(a)

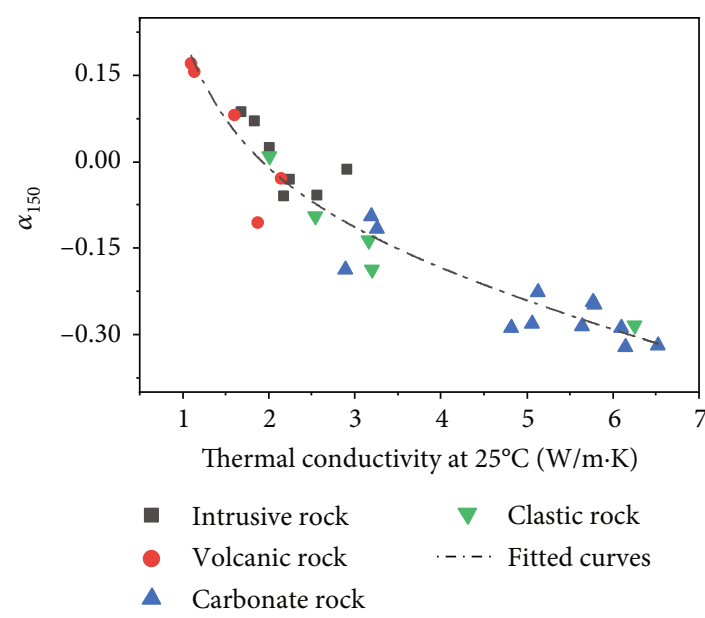

(c)

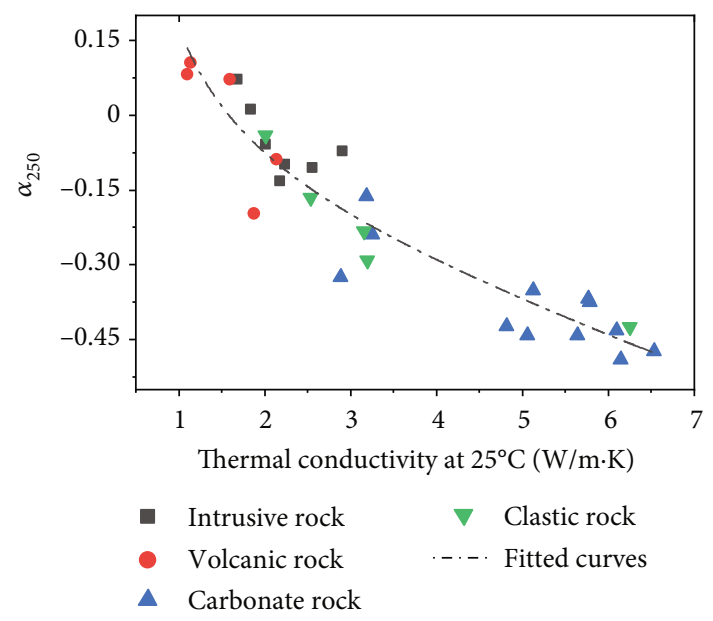

(e)

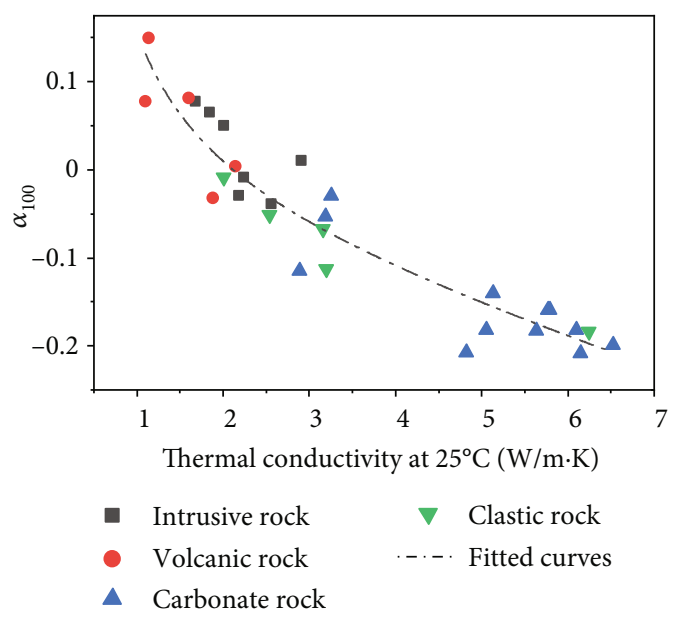

(b)

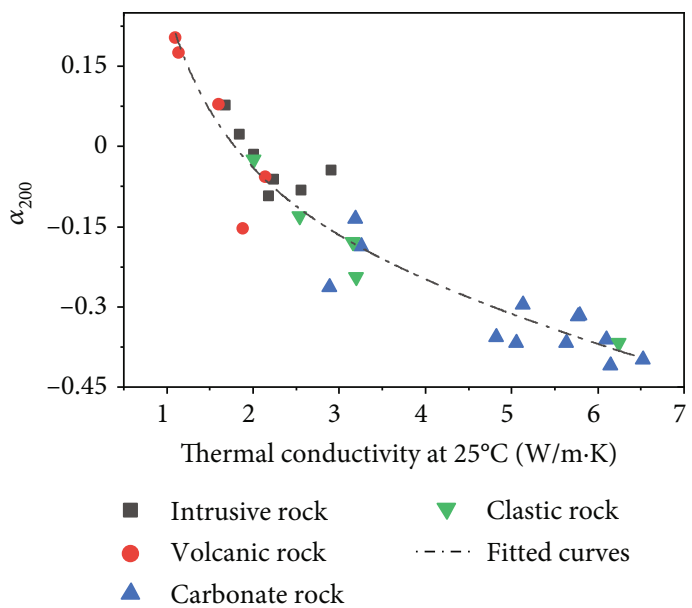

(d)

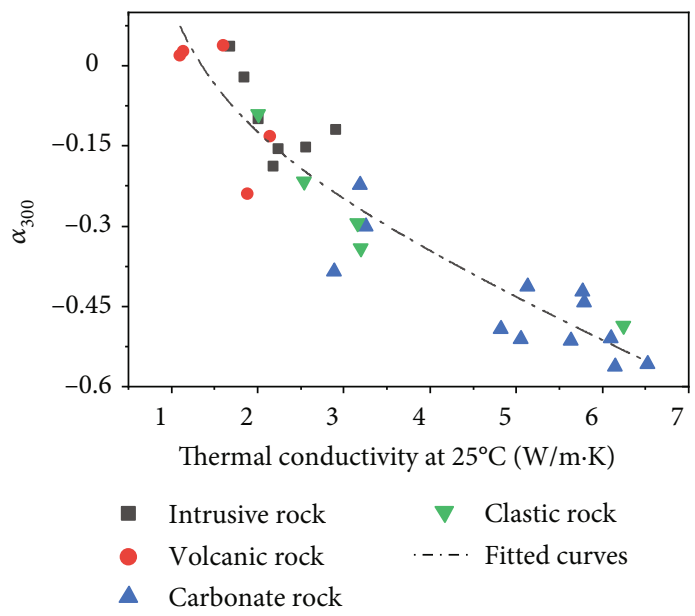

(f)

Figure 5: The rate of decrease at various temperature against the $\lambda$ at $25^{\circ} \mathrm{C}$. (a) $50^{\circ} \mathrm{C}$; (b) $100^{\circ} \mathrm{C}$; (c) $150^{\circ} \mathrm{C}$; (d) $200^{\circ} \mathrm{C}$; (e) $250^{\circ} \mathrm{C}$; (f) $300^{\circ} \mathrm{C}$ The dashed lines represent the fitted line.

the corrected and measured values are plotted in Figure 6. A conclusion can be easily reached. The value of thermal conductivity at room temperature is a more critical factor to govern the extent of temperature effect rather than the depth.
The limestones with low original thermal conductivity are slightly influenced by temperature even though they are at considerable depth. By contrast, the dolomites with high thermal conductivity have a remarkable decrease in thermal 
TABLE 3: The values of the fitting parameters for the decrease rate $(\alpha)$ at various temperature.

\begin{tabular}{lcccc}
\hline & $a$ & $b$ & $c$ & $R^{2}$ \\
\hline $50^{\circ} \mathrm{C}$ & $-0.01444 \pm 0.00498$ & $0.08651 \pm 0.04337$ & $-0.00561 \pm 0.03294$ & 0.80097 \\
$100^{\circ} \mathrm{C}$ & $-0.03029 \pm 0.00801$ & $0.23097 \pm 0.06970$ & $-0.04518 \pm 0.05295$ & 0.89418 \\
$150^{\circ} \mathrm{C}$ & $-0.04224 \pm 0.01169$ & $0.38260 \pm 0.10214$ & $-0.11632 \pm 0.07779$ & 0.90605 \\
$200^{\circ} \mathrm{C}$ & $-0.03891 \pm 0.01200$ & $0.52731 \pm 0.10488$ & $-0.22392 \pm 0.07988$ & 0.92430 \\
$250^{\circ} \mathrm{C}$ & $-0.06120 \pm 0.01501$ & $0.37454 \pm 0.13119$ & $-0.13597 \pm 0.09992$ & 0.89551 \\
$300^{\circ} \mathrm{C}$ & $-0.07244 \pm 0.01619$ & $0.31727 \pm 0.14151$ & $-0.13183 \pm 0.10777$ & 0.88988 \\
\hline
\end{tabular}

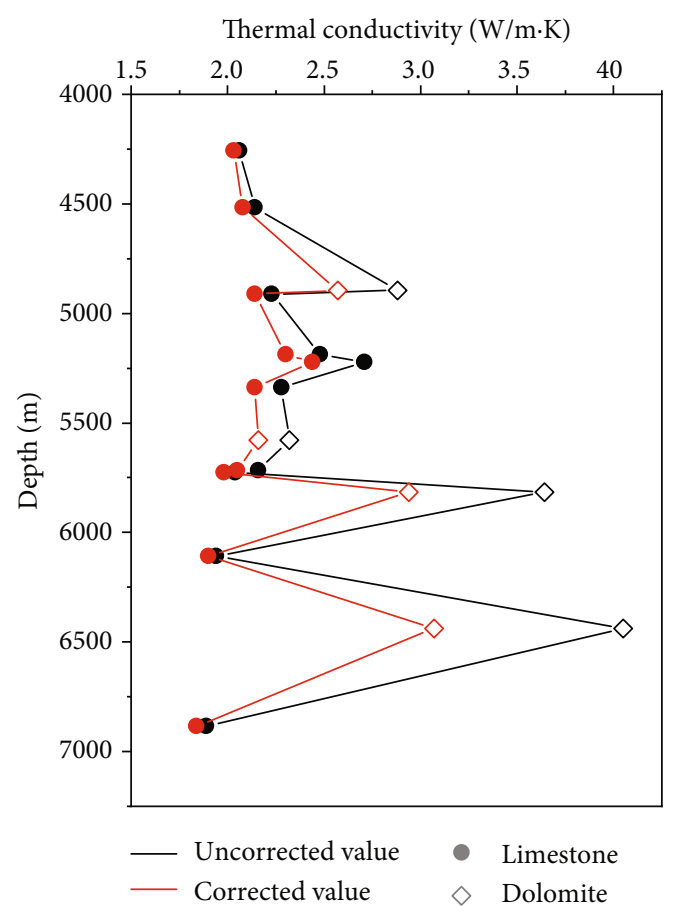

FIGURE 6: Comparison between the corrected values and the uncorrected values.

conductivity even though they have swallow depth. The thermal conductivity for the dolomite with $4.05 \mathrm{~W} / \mathrm{m} \cdot \mathrm{K}$ decreases by approximately one-fourth. Such a large discrepancy may cause a significant error in temperature profile and heat flow calculation in a basin and must be reasonably treated. Together, if a sample has a low thermal conductivity $(<2.20 \mathrm{~W} / \mathrm{m} \cdot \mathrm{K})$ at room environment, the correction can be omitted. On the contrary, for the rocks having a high thermal conductivity $(>2.70 \mathrm{~W} / \mathrm{m} \cdot \mathrm{K})$, the temperature-driven effect should be taken into consideration. The correction is a feasible approach; however, measurement in situ is, by contrast, the most accurate one. It is necessary to develop in situ measurement techniques to determine the thermal conductivity of deep buried rocks.

The corrected results are examined by continuous temperature logging data and thermal conductivity. The temperature profile and stratigraphic column of the well Zhong 4 in Tarim Basin are collected (Figure 9). Temperature gradient decreases considerably at $5400 \mathrm{~m}$ depth from $22.9^{\circ} \mathrm{C} / \mathrm{km}$ to $14.7^{\circ} \mathrm{C} / \mathrm{km}$, which is derived from the great discrepancy between the upper and lower strata in thermal conductivity. The upper strata is composed of sandstone, mudstone, and limestone. According to the previous data of thermal conductivity in the Tazhong area of Tarim Basin [34] and the thickness of corresponding rocks, the average thermal conductivity of the upper strata is attained by calculating the weighted harmonic mean, and it is $2.34 \mathrm{~W} / \mathrm{m} \cdot \mathrm{K}$. The lower strata of dolomite has a mean thermal conductivity of $4.03 \mathrm{~W} / \mathrm{m} \cdot \mathrm{K}$. Then, the heat flow can be acquired, being $53.59 \mathrm{~mW} / \mathrm{m}^{2}$ and $59.24 \mathrm{~mW} / \mathrm{m}^{2}$ through the upper and lower strata, respectively. The difference stems from the uncorrected thermal conductivity of the lower strata. Because of the hot temperature and greater thermal conductivity in lower strata, it is necessary to take into temperature effect on thermal conductivity account. Contrary to this, the upper strata have a low thermal conductivity, and the circumstance temperature is also low. Both two factors commonly lead to the weak temperature effect. According to the foregoing method, thermal conductivity of the lower strata is corrected as $3.25 \mathrm{~W} / \mathrm{m} \cdot \mathrm{K}$. With the corrected value, the recalculated heat flow is $47.78 \mathrm{~mW} / \mathrm{m}^{2}$, slightly less than that of the upper strata. This is due to the radioactive heat generation in rocks. Radiogenic heat production rate of rocks in Tarim Basin approximates $1.17 \mu \mathrm{W} / \mathrm{m}^{3}$ [35]. Based on this, the contribution of radiogenic heat of the upper strata to heat flow can be obtained by the radiogenic heat production rate multiplied by the thickness of strata, and it is $6.43 \mathrm{~mW} / \mathrm{m}^{2}$. Adding $6.43 \mathrm{~mW} / \mathrm{m}^{2}$ to $47.78 \mathrm{~mW} / \mathrm{m}^{2}$, the total heat flow is obtained and $54.21 \mathrm{~mW} / \mathrm{m}^{2}$, which is essentially equal to the value of $53.59 \mathrm{~mW} / \mathrm{m}^{2}$. The agreement indicates that it is necessary to correct thermal conductivity of rocks under high temperature, especially for those rocks with great thermal conductivity.

\section{Conclusion}

From the measured thermal conductivity of twenty-eight samples, the following conclusion can be derived:

(1) Thermal conductivity of samples at $25^{\circ} \mathrm{C}$ reveals that the average of $\lambda$ for carbonate and clastic rocks is greater than that of intrusive rocks and volcanic rocks. In spite of it, various lithology rocks may still be overlap each other to a great extent due to numerous factors to exert a critical effect on $\lambda$ of rocks 
TABLe 4: The depth and thermal conductivity of samples at Tarim Basin [2].

\begin{tabular}{|c|c|c|c|c|c|c|}
\hline Lithology & Depth (m) & $\begin{array}{c}\text { Estimated } \\
\text { temperature }\left({ }^{\circ} \mathrm{C}\right)\end{array}$ & Porosity (\%) & Fluid & $\begin{array}{l}\text { Thermal conductivity } \\
(\mathrm{W} / \mathrm{m} \cdot \mathrm{K})\end{array}$ & $\begin{array}{c}\text { Estimated thermal } \\
\text { conductivity }(\mathrm{W} / \mathrm{m} \cdot \mathrm{K})\end{array}$ \\
\hline Dolomite & 6438 & 192 & 0.9 & Poor & 4.05 & 3.07 \\
\hline Dolomite & 5815 & 175 & 1.8 & Poor & 3.64 & 2.94 \\
\hline Dolomite & 4894 & 150 & 1.1 & Poor & 2.88 & 2.57 \\
\hline Dolomite & 5579 & 169 & 4.5 & Poor & 2.32 & 2.16 \\
\hline Limestone & 5158 & 158 & 2.5 & Rich & 2.48 & 2.30 \\
\hline Limestone & 4911 & 151 & 4.3 & Rich & 2.23 & 2.14 \\
\hline Limestone & 4515 & 140 & 0.9 & Poor & 2.14 & 2.08 \\
\hline Limestone & 5221 & 159 & 4.5 & Poor & 2.71 & 2.44 \\
\hline Limestone & 4257 & 133 & Void & Poor & 2.06 & 2.03 \\
\hline Limestone & 5337 & 162 & 7.0 & Poor & 2.28 & 2.14 \\
\hline Limestone & 5716 & 172 & 5.0 & Rich & 2.16 & 2.05 \\
\hline Limestone & 6109 & 183 & 2.2 & Rich & 1.94 & 1.90 \\
\hline Limestone & 5727 & 173 & 5.0 & Rich & 2.04 & 1.98 \\
\hline Limestone & 6885 & 204 & 3.7 & Poor & 1.89 & 1.84 \\
\hline
\end{tabular}

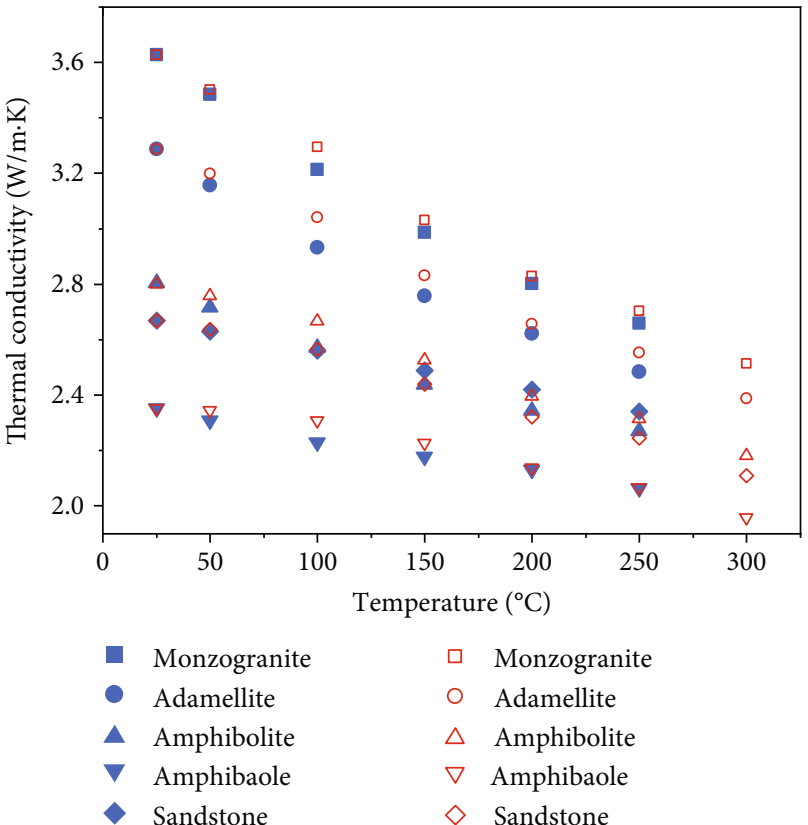

FIgURE 7: Comparation of experimentally measured values with estimated values. The bule denotes the measured values. The red denotes the estimated values. Sandstone is from [22], and the remaining samples are from [6].

(2) The experiment under high temperature demonstrates that the $\lambda-T$ curves can be divided into three categories relying on the value of $\lambda$ at $25^{\circ} \mathrm{C}$ regardless of lithology. With a great $\lambda$ above $4.5 \mathrm{~W} / \mathrm{m} \cdot \mathrm{K}$ at $25^{\circ} \mathrm{C}$, the rocks have strongly decreased $\lambda$ with increasing temperature, and the $\lambda-T$ curves gradually slow down. If lying from $2.5 \mathrm{~W} / \mathrm{m} \cdot \mathrm{K}$ to $3.5 \mathrm{~W} / \mathrm{m} \cdot \mathrm{K}$, the $\lambda$ shows a linear decrease. When below $2.5 \mathrm{~W} / \mathrm{m} \cdot \mathrm{K}$, the $\lambda$ slightly increases from room temperature to $150^{\circ} \mathrm{C}$ and then decreases at remaining temperature range. The phenomenon may be explained by the fact

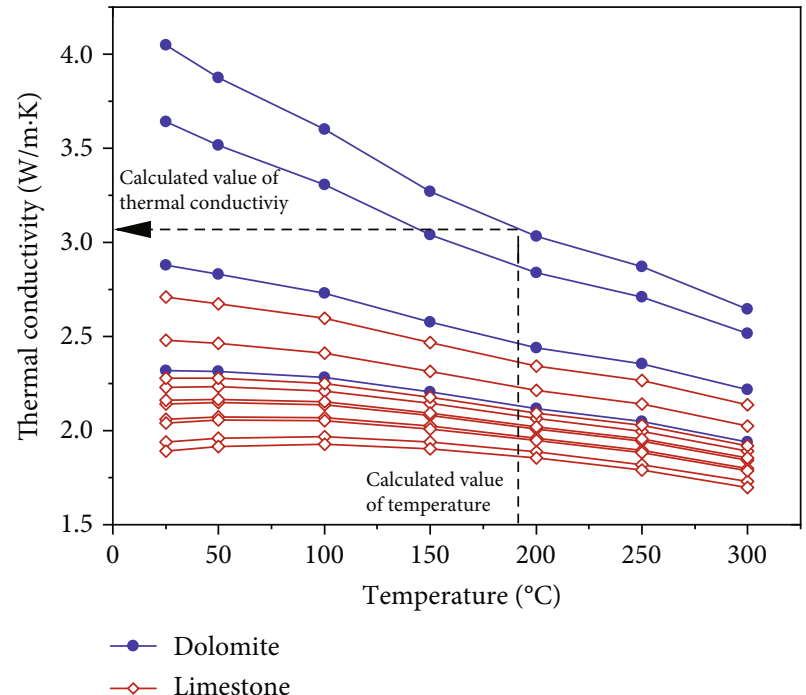

Figure 8: Estimated values of thermal conductivity in Tarim Basin.

that the silicate material with similar the $\lambda$ at room temperature may exhibit analogous respondence of the $\lambda$ to temperature. While deviating significantly in mineralogy, chemical structure, elements, etc., different types of rock can be taken as the silicatebearing material and therefore is constrained by the heat transfer law of silicate

(3) The correction of thermal conductivity in Tarim Basin suggests that the effect of temperature on thermal conductivity depends strongly on its value at room temperature, instead of depth at which the sample lied. Although pressure and fluid can affect thermal conductivity as well, their effect can be ignored compared with that of temperature in present condition. The correction of thermal conductivity is necessary for those rocks with high thermal conductivity under high temperature 


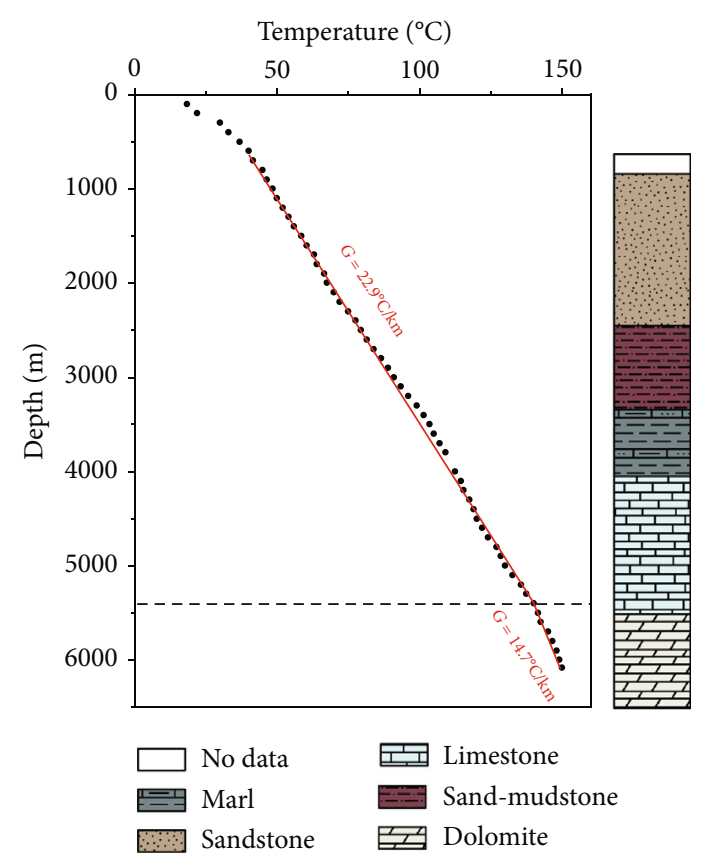

Figure 9: Temperature profile and stratigraphic column of the well Zhong 4.

\section{Data Availability}

The data used to support the findings of this study are available from the first author upon request. First author: ChiChen; email: chenchigeosci@foxmail.com.

\section{Conflicts of Interest}

The authors declare no conflict of interest.

\section{Acknowledgments}

The authors disclosed receipt of the following financial support for the research, authorship, and/or publication of this article: this study was supported by the "National Natural Science Foundation of China" (Grant no. 41772248), "National Science and Technology Major Project of China" (Grant no. 2017ZX05008004), and the "National Key R\&D Program of China” (Grant no. 2018YFC0604302).

\section{References}

[1] M. Abid, U. Hammerschmidt, and J. Köhler, “Temperature and moisture dependent thermophysical properties of Sander sandstone," International Journal of Thermal Sciences, vol. 86, pp. 88-94, 2014.

[2] X. Li, S. Liu, and C. Feng, "Thermal properties of sedimentary rocks in the Tarim Basin, northwestern China," AAPG Bulletin, vol. 103, no. 7, pp. 1605-1624, 2019.

[3] S. Q. Miao, H. P. Li, and G. Chen, "Temperature dependence of thermal diffusivity, specific heat capacity, and thermal conductivity for several types of rocks," Journal of Thermal Analysis and Calorimetry, vol. 115, no. 2, pp. 1057-1063, 2014.

[4] A. E. Ramazanova and S. N. Emirov, "Effect of pressure and temperature on the thermal conductivity of siltstone and dolo- mite," Bulletin of Russian Academy of Science, vol. 76, no. 1, article 177, pp. 125-127, 2012.

[5] A. G. Whittington, A. M. Hofmeister, and P. I. Nabelek, "Temperature-dependent thermal diffusivity of the Earth's crust and implications for magmatism," Nature, vol. 458, no. 7236, pp. 319-321, 2009.

[6] F. Birch and H. Clark, "The thermal conductivity of rocks and its dependence upon temperature and composition," American Journal of Science, vol. 238, no. 8, pp. 529-558, 1940.

[7] H.-D. Vosteen and R. Schellschmidt, "Influence of temperature on thermal conductivity, thermal capacity and thermal diffusivity for different types of rock," Physics and Chemistry of the Earth, vol. 28, no. 9-11, pp. 499-509, 2003.

[8] I. M. Abdulagatov, S. N. Emirov, Z. Z. Abdulagatova, and S. Y. Askerov, "Effect of pressure and temperature on the thermal conductivity of rocks," Journal of Chemical \& Engineering Data, vol. 51, no. 1, pp. 22-33, 2006.

[9] Y. A. Popov, D. F. C. Pribnow, J. H. Sass, C. F. Williams, and H. Burkhardt, "Characterization of rock thermal conductivity by high-resolution optical scanning," Geothermics, vol. 28, no. 2, pp. 253-276, 1999.

[10] K. Manohar, D. W. Yarbrough, and J. R. Booth, "Measurement of apparent thermal conductivity by the thermal probe method," Journal of Testing and Evaluation, vol. 28, no. 5, pp. 345-351, 2000.

[11] J. J. Healy, J. J. de Groot, and J. Kestin, "The theory of the transient hot-wire method for measuring thermal conductivity," Physica B+C, vol. 82, no. 2, pp. 392-408, 1976.

[12] H. E. Khalifa, J. Kestin, and W. A. Wakeham, "The theory of the transient hot-wire cell for measuring the thermal conductivity of gaseous mixtures," Physica A Statal Mechanics \& Its Applications, vol. 97, no. 2, pp. 273-286, 1979.

[13] S. E. Gustafsson, "Transient plane source techniques for thermal conductivity and thermal diffusivity measurements of solid materials," Review of Scientific Instruments, vol. 62, no. 3, pp. 797-804, 1991.

[14] K. I. Horai, “Thermal conductivity of rock-forming minerals," Journal of Geophysical Research, vol. 76, pp. 1278-1308, 1971.

[15] C. Clauser and E. Huenges, Thermal Conductivity of Rocks and Minerals, American Geophysical Union., Washington, USA, 1995.

[16] D. Pribnow, C. F. Williams, J. H. Sass, and R. Keating, “Thermal conductivity of water-saturated rocks from the KTB Pilot Hole at temperatures of 25 to $300^{\circ} \mathrm{C}$," Geophysical research letters, vol. 23, no. 4, pp. 391-394, 1996.

[17] U. Seipold, "Depth dependence of thermal transport properties for typical crustal rocks," Physics of the Earth and Planetary Interiors, vol. 69, no. 3-4, pp. 299-303, 1992.

[18] W. H. Somerton, Thermal Properties and Temperature Related Behaviour of Rock/Fluid Systems, Elsevier, New York, 1992.

[19] I. M. Abdulagatov, S. N. Emirov, T. A. Tsomaeva, K. A. Gairbekov, S. Y. Askerov, and N. A. Magomedova, "Thermal conductivity of fused quartz and quartz ceramic at high temperatures and high pressures," Journal of Physics and Chemistry of Solids, vol. 61, no. 5, pp. 779-787, 2000.

[20] J. H. Sass, A. H. Lachenbruch, and R. J. Munroe, “Thermal conductivity of rocks from measurements on fragments and its application to heat-flow determinations," Journal of Geophysical Research, vol. 76, no. 14, pp. 3391-3401, 1971.

[21] K. I. Horai and J. I. Susaki, "The effect of pressure on the thermal conductivity of silicate rocks up to 12 kbar," Physics of the 
Earth and Planetary Interiors, vol. 55, no. 3-4, pp. 292-305, 1989.

[22] Z. Abdulagatova, I. M. Abdulagatov, and V. N. Emirov, "Effect of temperature and pressure on the thermal conductivity of sandstone," International Journal of Rock Mechanics and Mining Sciences, vol. 46, no. 6, pp. 1055-1071, 2009.

[23] A. E. Beck, D. M. Darbha, and H. H. Schloessin, "Lattice conductivities of single-crystal and polycrystalline materials at mantle pressures and temperatures," Physics of the Earth and Planetary Interiors, vol. 17, no. 1, pp. 35-53, 1978.

[24] J. Luo, J. Jia, H. Zhao et al., "Determination of the thermal conductivity of sandstones from laboratory to field scale," Environmental Earth Sciences, vol. 75, no. 16, 2016.

[25] P.-X. Liu, S.-B. Deng, P. Guan, Y.-Q. Jin, K. Wang, and Y.Q. Chen, "The nature, type, and origin of diagenetic fluids and their control on the evolving porosity of the Lower Cambrian Xiaoerbulak Formation dolostone, northwestern Tarim Basin, China," Petroleum Science, vol. 17, no. 4, pp. 873-895, 2020.

[26] G.-H. Yuan, Y.-C. Cao, J. Gluyas et al., "How important is carbonate dissolution in buried sandstones: evidences from petrography, porosity, experiments, and geochemical calculations," Petroleum Science, vol. 16, no. 4, pp. 729-751, 2019.

[27] K. Albert, M. Schulze, C. Franz, R. Koenigsdorff, and K. Zosseder, "Thermal conductivity estimation model considering the effect of water saturation explaining the heterogeneity of rock thermal conductivity," Geothermics, vol. 66, pp. 112, 2017.

[28] P. Nagaraju and S. Roy, "Effect of water saturation on rock thermal conductivity measurements," Tectonophysics, vol. 626, pp. 137-143, 2014.

[29] A. M. Hofmeister, "Mantle values of thermal conductivity and the geotherm from phonon lifetimes," Science, vol. 283, no. 5408, pp. 1699-1706, 1999.

[30] T. Li, C.-F. Wu, and Z.-W. Wang, "The dynamic change of pore structure for low-rank coal under refined upgrading pretreatment temperatures," Petroleum Science, vol. 18, no. 2, pp. 430-443, 2021.

[31] W. Lin, O. Tadai, T. Hirose et al., "Thermal conductivity of rocks under high pressure conditions," in Rock Mechanics for Resources, Energy and Environment, pp. 311-314, Taylor \& Francis Group, London, 2013.

[32] R. G. Ross, P. Andersson, B. Sundqvist, and G. Backstrom, "Thermal conductivity of solids and liquids under pressure," Reports on Progress in Physics, vol. 47, no. 10, pp. 1347-1402, 1984.

[33] S. Liu, X. Lei, C. Feng, and X. Li, "Heat flow, deep formation temperature and thermal structure of the Tarim Basin," in EGU General Assembly Conference Abstracts, Northwest China, 2016.

[34] C. Feng, S. Liu, L. Wang, and C. Li, "Present-day geotemperature field characteristics in the central uplift area of the Tarim Basin and implications for hydrocarbon generation and preservation," Earth Science-Journal of China University of Geoscience, vol. 35, pp. 645-656, 2010.

[35] X. Luo, C. Zhu, B. Zhang, B. Tang, and T. Chen, "Heat production rate calculation using gamma- ray logging of the sedimentary formation in the Tarim basin, Northwest China," Acta Geologica Sinica, vol. 94, pp. 2078-2088, 2020. 